\title{
Association between atrial fibrillation and red cell distribution width in patients with acute coronary syndrome
}

\author{
Akut koroner sendromlu hastalarda atriyal fibrilasyon ve eritrosit \\ dağılım genişliği arasındaki ilişki
}

\author{
Sinan CERŞiT, Macit KALÇIK, Lütfi ÖCAL, Emrah BAYAM
}

\begin{abstract}
Cardiovascular disease is associated with red cell distribution width (RDW), an indicator of variability in circulating erythrocyte volume. The inflammatory process in acute coronary syndrome (ACS) and atrial fibrillation (AF) may cause an increase in RDW. In this study, we purposed to investigate whether admission RDW is associated with AF in patients with ACS. This retrospective study included 50 patients with AF and 62 age-and sex-matched controls, who had presented with ACS between January 2016 to December 2017. All subjects had routine blood tests including common blood cell counts and also underwent physical examination and echocardiographic examination. Baseline characteristics were similar in the two groups. Left atrial (LA) diameter $(47 \pm 13$ vs $38 \pm 12 \mathrm{~mm}, \mathrm{p}<0.05)$ and $\mathrm{RDW}(14.5 \pm 2 \%$ vs. $12.6 \pm 1 \%$, $p<0.001)$ were significantly higher in the patients with AF than the control group. In multivariate analysis, LA diameter (Odds ratio- $O R=1.10,95 \%$ Confidence interval-Cl: 1.07-1.18, $p<0.05)$, RDW (OR=1.53, 95\% Cl: 1.12-1.98, $p<0.005)$ and troponin $T$ $(O R=1.13,95 \% \mathrm{Cl}: 1.1-1.15, p<0.05)$ were found to be significant independent predictors of AF in patients with ACS. A serum RDW level of $>11.7 \%$ predicted the presence of $A F$ with a sensitivity of $56 \%$ and a specificity of $64 \%(A \cup C=0.637, p<0.001)$. RDW is an inexpensive and readily available biomarker that may predict $A F$ in patients with ACS.
\end{abstract}

Keywords: Acute coronary syndrome, atrial fibrillation, red cell distribution width

\begin{abstract}
öz
Kardiyovasküler hastalıklar, kandaki eritrositlerin hacimlerindeki değişkenliğin göstergesi olan eritrosit dağılım genişliğinin (EDG) artışı ile ilişkilendirilmektedir. Enflamasyona bağlı olarak akut koroner sendrom (AKS) ve atriyal fibrilasyon (AF) gibi durumlar $E D G$ 'de artışa neden olabilir. Çalışmamızda, AKS ile hastaneye başvuran hastalardaki eşlik eden AF'nin EDG ile ilişkisini araştırdık. Ocak 2016-Aralık 2017 tarihleri arasındaki AKS ile başvuran AF mevcut olan 50 hasta ve, yaş ve cinsiyet yönünden eşleştirilmiş 62 kontrol hastası retrospektif olarak değerlendirildi. Tüm hastalara ayrıntılı fizik muayene ve ekokardiyografik görüntüleme uygulandı. Ayrıca, tam kan sayımını içeren rutin kan örnekleri alındı. Her iki grup arasında temel klinik özellikler benzerdi. Sol atriyal (SA) çap $(47 \pm 13$ ve $38 \pm 12 \mathrm{~mm}, p<0,05)$ ve ortalama EDG $(\% 14,5 \pm 2$ ve $\% 12,6 \pm 1, p<0,001)$ AF olan hastalarda kontrol grubuna göre anlamlı olarak daha yüksekti. Regresyon analizinde, $S A$ çap (Odds oranı-OO=1,10, \%95 Güven aralığı-GA: 1,07-1,18, $p<0,05)$, EDG (OO: 1,53, \%95 GA: 1,12-1,98, $p<0,005)$ ve troponin $T(O O=1,13,95 \%$ GA: 1,1-1,15, $p<0,05) A F^{\prime}$ nin bağımsız öngördürücüleri olarak bulundu. Serum EDG düzeyinin $>\% 11,7$ olması $A F$ varlığını \%56 duyarlılık ve \%64 özgüllük ile öngördü (EAA=0,637, $p<0,001)$. EDG ucuz ve kolay ulaşılabilir bir biyobelirteçtir. Yüksek $E D G, A K S$ ile başvuran hastalarda AF varlığını öngörebilir.
\end{abstract}

Anahtar kelimeler: Akut koroner sendrom, atriyal fibrilasyon, eritrosit dağılım genişliği

(TNF- $\alpha$ ), interlökinler (IL) gibi bazı enflamatuvar belirteçler AKS ve AF patogenezinde rol oynamaktadır ${ }^{4}$.

Akut koroner sendrom (AKS) tedavisindeki önemli gelişmelere rağmen, atriyal fibrilasyon (AF) önemli bir risk faktörü olmaya devam etmektedir. AKS ve eşlik eden $\mathrm{AF}^{\prime}$ de enflamasyonun rolü iyi bilinmektedir ${ }^{1-3}$. C-reaktif protein (CRP), tümor nekrozis faktör- $\alpha$
Yeni enflamasyon belirteçlerinden olan eritrosit dağılım genişliği (EDG) tam kan sayımının bir parçası olup, eritrosit hacimlerindeki değişimlerin ölçülmesiyle hesaplanır ${ }^{5}$. Koroner Arter Hastalığı (KAH), akut

Received: 09.04.2018

Accepted: 02.05.2018

Kartal Koşuyolu Heart Training and Research Hospital, Istanbul, Turkey

Yazışma adresi: Sinan Cerşit, Kartal Koşuyolu Heart Training and Research Hospital, Istanbul, Turkey

e-mail: sinancersit@hotmail.com 
miyokart enfarktüsü gibi bazı kardiyovasküler hastalıklar (KVH) EDG'yi artırmaktadır6,7. Ayrıca, AF ve kalp yetersizliğinde (KKY) prognostik belirteç olduğu ortaya çıkmıştır ${ }^{8}$. Enflamasyon ve nörohümoral aracılar kırmızı hücre içindeki değiş̧iklikleri uyarır ve EDG artışına neden olur 9 .

Lippi ve ark., ${ }^{10}$ AKS tanısında EDG ve troponin T'nin birlikte ölçümlerinin tek başına troponin T ölçümünden daha etkili olduğunu göstermişlerdir. Ayrıca, EDG'nin akut miyokardiyal enfarktüste önemli öngördürücü olduğu kanıtlanmıştır ${ }^{11}$. Ancak, AF'si olan AKS hastaları ile ilgili güncel çalışmalar bulunmamaktadır. Çalışmamızda, EDG'nin AKS hastalarındaki AF ile olan ilişkisini araştırdık.

\section{GEREÇ ve YÖNTEM}

Çalışmada Ocak 2016-Aralık 2017 tarihleri arasında AKS tanısı olan hastalar, retrospektif olarak incelendi. Hastalar, yaş ve cinsiyet eşleşmesi sağlanarak AF olan ve olmayan AKS olarak iki gruba ayrıldı. ST yükselmeli olmayan AKS tanısı, Avrupa Kardiyoloji Derneği kılavuzlarının kriterlerine göre konmuştur ${ }^{12}$. STEMI, anstabil anjina pektoris, doğumsal kalp hastalığı, hematolojik hastalık, aktif kronik infeksiyon, konnektif doku hastalıkları, yakın zamanda kan transfüzyon öyküsü olanlar, otoimmün hastalık, malign neoplazmlar, böbrek yetersizliği ve tiroid bozuklukları çalışmaya alınmadı. Tüm hastalara fizik muayene, elektrokardiyografi ve laboratuvar analiz uygulandı. KAH için eşlik eden risk faktörleri tarandı.

Biyokimyasal ve hematolojik parametreler için basvuru sırasında venöz kan örnekleri alındı. Standart tam kan sayımı içinde bulunan EDG analizi için otomatik kan sayım cihazı (ADVIA 2120i Hematology System, Siemens Healthcare Diagnostics, Deerfield, Illinois) kullanıldı.

İki boyutlu ölçümler, M-mode ve Doppler değerlendirmeleri transtorasik ekokardiyografi cihazı (iE33 Philips Medical Systems, Andover, MA, USA) ile tüm hastalara uygulandı. Sol ventriküler ejeksiyon fraksiyonu (LVEF), modifiye Simpson kuralına göre iki ve dört boşluklu apikal görüntüler kullanılarak hesaplandı.

Tüm katılımcılar bilgilendirilmiş onam formlarını kabul etti. Çalışma protokolü için yerel Etik Kurulu onayı alındı.

\section{İstatistiksel Analiz}

İstatistiksel analiz SPSS 19.0 istatistik programı ile uygulandı. Veri dağılımı Kolmogorov-Smirnov testi ile değerlendirildi. Normal dağılan devamlı değişkenler, ortalama \pm standart sapma ile raporlandı. Kategorik değişkenler sıklık ve yüzde (\%) olarak belirtildi. Sürekli değişkenler Student's t testi veya Mann-Whitney U testi ile, kategorik değişkenler ise $\chi^{2}$ testi kullanılarak karşılaştırıldı. AF eşlik eden AKS hastaları ile değişkenler arasındaki bağımsız ilişkilerini bulmak için lojistik regresyon analizi yapıldı. "Receiver Operator Characteristic (ROC)" analizi, AKS grubundaki AF varlığını tahmin etmede EDG'nin duyarlılığı ve özgüllügünü değerlendirmek için yapıldı. $P<0,05$ değeri istatistiksel olarak anlamlı olarak değerlendirildi.

\section{BULGULAR}

Bu çalışmada, AF'si olan 50 AKS hastası (28 (\%56) er-

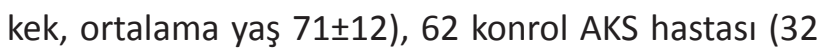

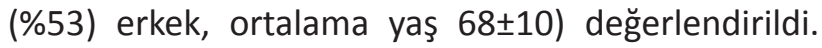
Her iki grubun temel özellikleri Tablo 1'de gösterildi. Gruplar arasında yaş, cinsiyet, hipertansiyon sıklığı, sigara kullanımı, diabetes mellitus, kreatinin, hemoglobin düzeylerinde ve sol ventriküler diastolik ve sistolik çaplar ve LV EF'yi içeren ekokardiyografik ölçümlerde her iki grup arasında anlamlı fark yoktu.

Troponin T düzeyleri $(4,5 \pm 4,6$ ve $2,8 \pm 2 \mathrm{ng} / \mathrm{mL}$, $p<0,001)$, EDG $(\% 14,5 \pm 2$ ve $\% 12,6 \pm 1, p<0,001)$, platelet değerleri $(287 \pm 126$ ve $252 \pm 74 \times 1,000 / u L$, $p<0,05)$ ve SA çap $(4,7 \pm 2,3$ vs $3,8 \pm 1,2, p<0,05) A F$ olan grupta kontrol grubuna göre anlamlı olarak daha yüksek saptandı (Tablo 1). Regresyon analizinde, EDG (Odds oranı-OO:1,53, \%95 Güven aralığı$\mathrm{GA}: 1,12-1,98, p<0,005)$, troponin $\mathrm{T}(\mathrm{OO}=1,13, \% 95$ GA $1,1-1,15, p<0,05)$ ve sol atriyal (SA) çap $(O O=1,10$, 
Tablo 1. AKS hastalarında AF mevcut olan ve olmayanların temel özellikleri.

\begin{tabular}{llll}
\hline & AF (+), $\mathbf{n = 5 0}$ & AF (-), n=62 & P değeri \\
\hline Yaş (yıl) & $71 \pm 12$ & $68 \pm 10$ & 0,2 \\
Erkek cinsiyet, n (\%) & $28(56)$ & $32(53)$ & 0,18 \\
Hipertansiyon, $\mathrm{n}(\%)$ & $14(28)$ & $15(24)$ & 0,22 \\
Diabetes Mellitus, n (\%) & $9(18)$ & $10(17)$ & 0,45 \\
Sigara, $\mathrm{n}(\%)$ & $16(32)$ & $18(29)$ & 0,43 \\
Hemoglobin (g/dL) & $11,6 \pm 1,7$ & $12.5 \pm 1$ & 0,11 \\
EDG (\%) & $15,4 \pm 2$ & $13,3 \pm 1$ & $<0,001$ \\
Platelet (x1.000/uL) & $287 \pm 126$ & $252 \pm 74$ & $<0,05$ \\
Beyaz küre (x1.000/uL) & $12,8 \pm 7$ & $12,4 \pm 5$ & 0,3 \\
Troponin T (ng/mL) & $4,5 \pm 4,6$ & $2,8 \pm 2$ & $<0,001$ \\
Kreatinin (mg/dL) & $1,1 \pm 0,5$ & $1 \pm 0,4$ & 0,09 \\
Ekokardiyografi & & & \\
SVDSÇ (mm) & $49,1 \pm 4,3$ & $45,8 \pm 3,2$ & 0,18 \\
SVSSÇ (mm) & $28,9 \pm 3,3$ & $28,6 \pm 3,9$ & 0,89 \\
LV EF (\%) & $62,9 \pm 4,2$ & $63,1 \pm 2,9$ & 0,82 \\
SA çap (mm) & $47 \pm 23$ & $38 \pm 12$ & $<0,05$ \\
& & & \\
\hline AKS: 0 (mutkoroner sendrom & &
\end{tabular}

AKS: akut koroner sendrom; AF: atriyal fibrilasyon; EDG: eritrosit dağılım genişliği; SVDSÇ: sol ventriküler diyastol sonu çap; SVSSÇ: sol ventriküler sistol sonu çap; LV EF: sol ventrikülenr ejeksiyon fraksiyonu; SA: sol atriyal.

Tablo 2. AKS hastalarında AF varlığını öngördüren parametrelerin çok değişkenli lojistik regresyon analizi ile değerlendirilmesi.

\begin{tabular}{llll}
\hline & Odds oranı & \%95 Güven aralığı & P değeri \\
\hline SA çap & 1.10 & $1.07-1.12$ & $<0.05$ \\
EDG & 1.57 & $1.12-2.03$ & $<0.005$ \\
Troponin & 1.03 & $1.01-1.04$ & 0.019
\end{tabular}

AKS: akut koroner sendrom; AF: atriyal fibrilasyon; EDG: eritrosit dağılım genişliği; SA: sol atriyal.

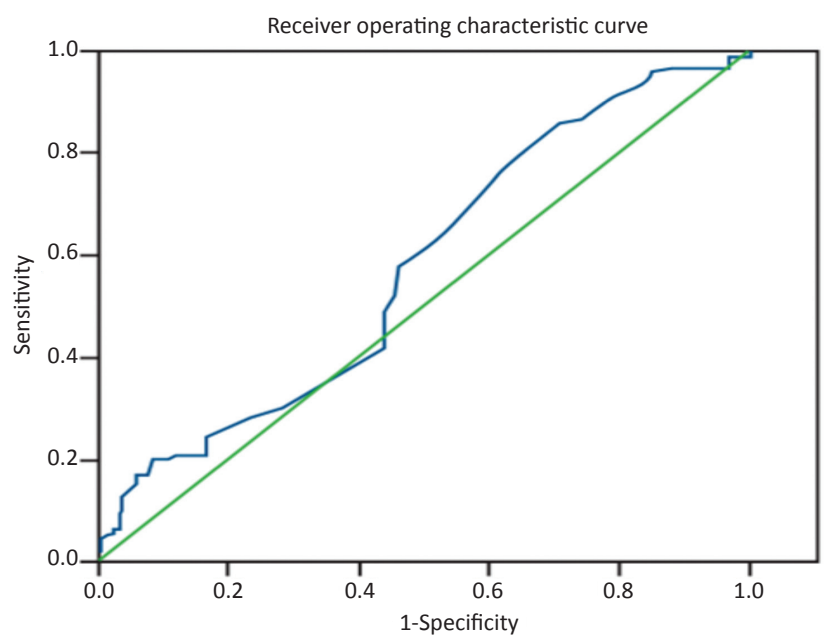

Şekil 1. Atriyal fibrilasyonun eşlik ettiği akut koroner sendromlu hastalarda eritrosit dağılım genişliğinin ROC (receiver operator characteristic) eğrisi analizleri.
\%95 GA:1,07-1,18, p<0,05) AF'nin bağımsız öngördürücüleri olarak bulundu (Tablo 2). Serum EDG düzeyinin $>\% 11,7$ olması AF varlığını \%56 duyarlılık ve $\% 64$ özgüllük ile öngördü (EAA=0,637, $p<0,001$ ) (Şekil 1).

\section{TARTIŞMA}

Çalışmamızda, EDG düzeylerinin AF'si olan AKS hastalarında kontrol grubuna göre anlamlı derecede daha yüksek olduğu gösterildi. Ayrıca SA çap, EDG ve troponin $T$ ölçümlerinin AF varlığının bağımsız öngördürücüleri olabileceği gösterildi.

AKS, KAH için önemli morbidite ve mortalite nedenidir. AKS'nin klinik prognozunda AF önemli yere sahiptir. AKS ve AF patofizyolojisinde enflamasyon belirgin şekilde rol oynar ${ }^{13-15}$. EDG ve KVH arasındaki ilişki ile ilgili olarak birtakım mekanizmalar öne sürülmüştür. Oksidatif stres ve enflamasyon dolaşımdaki eritrositlerin yarı ömrünü kısaltabilir, membran özelliklerin değiştirebilir ve buna bağlı olarak EDG artışına neden olabilir ${ }^{16}$. Yüksek EDG'nin kardiyovasküler mobidite ve mortaliteyi tahmin etmede yeni bir gösterge olduğu belirtilmiştir ${ }^{17-19}$. Ayrıca son çalışmalar, yüksek EDG düzeylerinin AKS hastalarında hastane içi ölüm, uzun dönem mortalite ve koroner olaylar ile bağımsız şekilde ilişkili olduğunu belirlemişlerdir ${ }^{20-22}$. Förhecz ve ark., ${ }^{23}$ EDG değeri yüksek olan KKY hastalarında CRP, eritropoetin ve IL-6 düzeylerinin daha yüksek çıktığını göstermişlerdir. KVH'de ısrarlı EDG artışı hipoksik durumlara bağlanmaktadır ${ }^{24}$. Eritrositler dokulara oksijen taşıma dışında, kardiyovasküler regulasyona etki eden bazı ekstraselüler mediyatörler salmaktadırlar. Eritrolizis sonucunda kalbe olumsuz etkide bulunan serbest radikaller açığa çıkmaktadır. Bu yıkıma bağlı gelişen patofizyolojik süreç, kardiyovasküler doIaşıma irili ufaklı boyutlarda eritrositlerin salınmasına neden olmaktadır. Bu durum anizositoz olarak bilinmektedir. Enflamasyon demir metabolizma dengesini bozarak veya eritropoetin üretimini önleyerek EDG artışına neden olabilir ${ }^{25-28}$.

Ertaş G ve ark., ${ }^{29}$ yüksek EDG'nin enflamasyon göstergesi olarak benzer mekanizmalara bağlı olarak atriyal fibrilasyonla ilişkili olduğunu bulmuşlardır. 
Liu ve ark.'nın ${ }^{30}$ yürüttüğü bir çalışmada, paroksismal AF hastalarında EDG'nin kontrol hastalarına göre daha yüksek olduğu gösterilmiştir (\%12,7 ve \%12,4, $p<0,05)$.

Çalışmamızın sonuçlarına dayanarak, ortalama EDG düzeyleri, AF olan AKS hastalarında daha yüksek saptanmakla birlikte, bu durumun enflamasyona bağı gelişip gelişmediğini veya yüksek EDG oranlarınnın AF gelişimine neden olabildiğini kestirmek kolay değildir.

Çalışmamızda bazı kısıtlılıklar vardı, öncelikle geriye dönük bir çalışmaydı. Bunun yanında, istatistiksel analiz için EDG'nin başvurudaki anlık değeri kullanıldı ve takiplerde gözlenebilecek değişiklikler göz önüne alınmadı. CRP, IL-6, TNF- $\alpha$ gibi iyi bilinen enflamatuvar göstergelerle EDG'nin karşılaştırılması yapılmadı. Randomize kontrollü geniş ölçekli çalışmalarla bulgularımızın desteklenmesi gerekmektedir.

Sonuç olarak, hastaneye başvuruda ölçülen EDG'nin AF bulunan AKS hastalarında anlamlı olarak daha yüksek olduğu bulduk. AKS hastalarında artmış EDG, AF'yi öngörmede kullanılabilir.

\section{KAYNAKLAR}

1. Bekler A, Tenekecioğlu E, Erbağ G, Temiz A, Altun B, Barutçu $A$, et al. Relationship between red cell distribution width and long-term mortality in patients with non-ST elevation acute coronary syndrome. Anatol J Cardiol. 2015;15:634-9. https://doi.org/10.5152/akd.2014.5645

2. Zalawadiya SK, Veeranna V, Niraj A, Pradhan J, Afonso L. Red cell distribution width and risk of coronary heart disease events. Am J Cardiol. 2010;106:988-93. https://doi.org/10.1016/j.amjcard.2010.06.006

3. Güngör B, Özcan KS, Erdinler İ, Ekmekçi A, Alper AT, Osmonov $D$, et al. Elevated levels of RDW is associated with non-valvular atrial fibrillation. J Thromb Thrombolysis. 2014;37:404-10. https://doi.org/10.1007/s11239-013-0957-1

4. Lappe JM, Horne BD, Shah SH. Red cell distribution width, C-reactive protein, the complete blood count, and mortality in patients with coronary disease and a normal comparison population. Clin Chim Acta. 2011:412:2094-9. https://doi.org/10.1016/j.cca.2011.07.018

5. Isik T, Uyarel H, Tanboga IH, Kurt M, Ekinci M, Kaya A, et al. Relation of red cell distribution width with the presence, severity, and complexity of coronary artery disease. Coron Artery Dis. 2012;23:51-6. https://doi.org/10.1097/MCA.0b013e32834e4f5c

6. Uyarel H, Ergelen M, Cicek G, Kaya MG, Ayhan E, Turkkan C, et al. Red cell distribution width as a novel prognostic marker in patients undergoing primary angioplasty for acute myocardial infarction. Coron Artery Dis. 2011;22:138-44. https://doi.org/10.1097/MCA.0b013e328342c77b

7. Gürsoy OM, Karakoyun S, Kalçık M, Gökdeniz T, Yesin M, Gündüz $\mathrm{S}$, et al. Usefulness of novel hematologic inflammatory parameters to predict prosthetic mitral valve thrombosis. American Journal of Cardiology. 2014;113:860-4. https://doi.org/10.1016/j.amjcard.2013.11.029

8. Ozcan F, Turak O, Durak A, Işleyen A, Uçar F, Giniş Z, et al. Red cell distribution width and infammation in patients with nondipper hypertension. Blood Press. 2013;22:80-5. https://doi.org/10.3109/08037051.2012.707336

9. Szmitko PE, Wang $\mathrm{CH}$, Weisel RD, de Almeida JR, Anderson TJ, Verma S. New markers of inflammation and endothelial cell activation. Circulation. 2003;108:1917-23. https://doi.org/10.1161/01.CIR.0000089190.95415.9F

10. G Lippi, L Filippozzi, M Montagnana, Salvagno GL, Franchini M, Guidi GC, et al. Clinical usefulness of measuring red blood cell distribution width on admission in patients with acute coronary syndromes. Clinical Chemistry and Laboratory Medicine. 2009:47:353-7. https://doi.org/10.1515/CCLM.2009.066

11. F Akin, N Köse, B Ayça Katkat F, Duran M, Uysal OK, et al. Relation between red cell distribution width and severity of coronary artery disease inpatients with acute myocardial infarction. Angiology. 2013:64:592-6. https://doi.org/10.1177/0003319712461931

12. Roffi M, Patrono C, Collet JP, Mueller C, Valgimigli M, Andreotti F, et al. 2015 ESC Guidelines for the management of acute coronary syndromes in patients presentingwithout persistent ST-segment elevation: Task Force for the Management of Acute Coronary Syndromes in Patients Presenting without Persistent ST-Segment Elevation of the European Society of Cardiology (ESC). ESC Scientific Document Group. Eur Heart J. 2016;37:267-315. https://doi.org/10.1093/eurheartj/ehv320

13. Tanboğa IH, Topçu S, Nacar T, Aksakal E, Kalkan K, Kiki I, et al. Relation of coronary collateral circulation with red cell distribution width in patients with non-ST elevation myocardial infarction. Clin Appl Thromb Hemost. 2014;20:411-5. https://doi.org/10.1177/1076029612470490

14. Fuster V, Moreno PR, Fayad ZA, Corti R, Badimon JJ. Atherothrombosis and highrisk plaque:part I:evolving concepts. J Am Coll Cardiol. 2005;46:937-54. https://doi.org/10.1016/j.jacc.2005.03.074

15. Güngör B, Ozcan KS, Ozpamuk Karadeniz F, Uluganyan M, Ekmekçi A, Alper AT, et al. Red cell distribution width is increased in patients with ascending aortic dilatation. Turk Kardiyol Dern Ars. 2014;42:227-35. https://doi.org/10.5543/tkda.2014.77508

16. Karabulut A, Uyarel H, Uzunlar B, Çakmak M. Elevated red cell distribution width level predicts worse post-interventional thrombolysis in myocardial infarction flow reflecting abnormal reperfusion in acute myocardial infarction treated with a primary coronary intervention. Coron Artery Dis. 2012;23:6872.

https://doi.org/10.1097/MCA.0b013e32834f1188

17. Niccoli G, Lanza GA, Spaziani C, Altamura L, Romagnoli E, Leone $\mathrm{AM}$, et al. Baseline systemic inflammatory status and no-reflow phenomenon after percutaneous coronary angioplasty for acute myocardial infarction. Int J Cardiol. 2007;3:306-11.

https://doi.org/10.1016/j.ijcard.2006.05.012 
18. Ustündağ M, Orak M, Güloğlu C, Sayhan MB, Alyan O, Kale $E$. Comparative diagnostic accuracy of serum levels of neutrophil activating peptide- 2 and pentraxin-3 versus troponin-I in acute coronary syndrome. Anadolu Kardiyol Derg. 2011;7:588-94.

19. Bodi V, Sanchis J, Nunez J, Mainar L, Minana G, Benet I, et al. Uncontrolled immune response in acute miyocardial infarction:Unraveling the thread. Am Heart J. 2008;156:106573. https://doi.org/10.1016/j.ahj.2008.07.008

20. Felker GM, Allen LA, Pocock SJ, Shaw LK, McMurray JJ, Pfeffer $M A$, et al. Red cell distribution width as a novel prognostic marker in heart failure: data from the CHARM Program and the Duke Databank. J Am Coll Cardiol. 2007;50:40-7. https://doi.org/10.1016/j.jacc.2007.02.067

21. Förhecz Z, Gombos T, Borgulya G, Pozsonyi Z, Prohaszka Z, Janoskuti L. Red cell distribution width in heart failure: prediction of clinical events and relationship with markers of ineffective erythropoiesis, inflammation, renal function, and nutritional state. Am Heart J. 2009;158:659-666. https://doi.org/10.1016/j.ahj.2009.07.024

22. Isik T, Uyarel H, Tanboga IH, Kurt M, Ekinci M, Kaya A, et al. Relation of red cell distribution width with the presence, severity, and complexity of coronary artery disease. Coron Artery Dis. 2012;23:51-6. https://doi.org/10.1097/MCA.0b013e32834e4f5c

23. Azab B, Torbey E, Hatoum H, Singh J, Khoueiry G, Bachir R, et al. Usefulness of red cell distribution width in predicting allcause long-term mortality after non-ST-elevation myocardial infarction. Cardiology. 2011;119:72-80. https://doi.org/10.1159/000329920

24. Yčas JW, Horrow JC, Horne BD. Persistent increase in red cell size distribution width after acute diseases: A biomarker of hypoxemia? Clin Chim Acta. 2015;448:107.

https://doi.org/10.1016/j.cca.2015.05.021

25. Emans ME, Gaillard CA, Pfster R, Tanck MW, Boekholdt SM, Wareham NJ, et al. Red cell distribution width is associated with physical inactivity and heart failure, independent of established risk factors, inflammation or iron metabolism; the EPIC-Norfolk study. Int J Cardiol. 2013;168:3550-5. https://doi.org/10.1016/j.ijcard.2013.05.002

26. Stone PH. Triggering myocardial infarction. N Eng J Med. 2004;351:1716-18. https://doi.org/10.1056/NEJMp048245

27. Steppich BA, Moog P, Matissek C, Wisniowski N, Kühle J, Joghetaei $\mathrm{N}$, et al. Cytokine profiles and $\mathrm{T}$ cell function in acute coronary syndromes. Atherosclerosis. 2007;190:443-51. https://doi.org/10.1016/j.atherosclerosis.2006.02.034

28. Ma FL, Li S, Li XL, Liu J, Qing P, Guo YL, et al. Correlation of red cell distribution width with the severity of coronary artery disease: a large Chinese cohort study from a single center. Chin Med J (Engl). 2013;126:1053-7.

29. Ertas G, Aydin C, Sönmez, Erdoğan E, Turfan M, Tasal A, et al. Red cell distribution width predicts new-onset atrial fibrillation after coronary artery bypass grafting. Scand Cardiovasc J. 2012.

30. Liu T, Shao Q, Miao S, Liu E, Xu G, Yuan R, et al. Red cell distribution width as a novel, inexpensive marker for paroxysmal atrial fibrillation. Int J Cardiol. 2014;171:e52-3. https://doi.org/10.1016/j.ijcard.2013.11.112 